\title{
The effect of the nitric oxide synthase inhibitor, L-NMMA, on sodium metabisulphite-induced bronchoconstriction and refractoriness in asthma
}

\author{
A.M. Hamad*, A. Wisniewski*, S.P. Range*, T. Small**, F. Holland*, A.J. Knox*
}

The effect of the nitric oxide synthase inhibitor, l-NMMA, on sodium metabisulphiteinduced bronchoconstriction and refractoriness in asthma. A.M. Hamad, A.Wisniewski, S.P. Range, T. Small, F. Holland, A.J. Knox. C ERS Journals Ltd 1999.

ABSTRACT: Refractoriness to indirect bronchoconstrictor stimuli, is a feature of asthma but the mechanism is poorly understood. This study tested the hypothesis that endogenous nitric oxide (NO) produced during a first bronchoconstrictor challenge protects against subsequent challenge and therefore has a role in the refractory process.

The effect of an NO synthase inhibitor, $N^{\mathrm{G}}$-mono-methyl-L-arginine (L-NMMA), on refractoriness to sodium metabisulphite (MBS) was investigated in 20 subjects with mild asthma. On visit one, the dose of MBS which caused a $20 \%$ fall in forced expiratory volume in one second (FEV1) (PD20) was determined. On visit two, the refractory index (RI) to MBS was determined by challenging the subjects twice with their PD20 of MBS, the second challenge proceeding after recovery from the first. Those showing a refractory index of $\sim 30 \%$ (10 subjects) inhaled either L-NMMA or placebo followed 5 min later by two challenges with their PD20 of MBS in a doubleblind cross over study at two further visits.

The dose of L-NMMA used was shown to reduce exhaled NO for a duration sufficient to cover the second MBS challenge However, no significant difference was found between L-NMMA and placebo in maximum fall in FEV1\% and area under the curve (AUC) during first or second MBS challenges or in RI on the two study days.

It is concluded that subjects with mild asthma show refractoriness to sodium metabisulphite, but that endogenous nitric oxide is unlikely to be involved either in the refractory process or in the response to sodium metabisulphite per se. Eur Respir J 1999; 14: 702-705.

\begin{abstract}
*Depts of Respiratory Medicine, City Hospital, Hucknall Road, Nottingham and ** Respiratory Medicine, Freeman Hospital, Freeman Road, Newcastle upon Tyne.
\end{abstract}

Correspondence: A.J. Knox

Respiratory Medicine Unit

City Hospital

Hucknall Road

Nottingham NG5 1PB

UK

Fax: 441158404771

Keywords: Asthma

bronchoprovocation

nitric oxide

L-NMMA

metabisulphite

refractoriness

Received: July 101997

Accepted after revision May 101999

A.M. Hamad was supported by the Egyptian Ministry of Higher Education. S Range was supported by the UK Medical Research Council.
Refractoriness, a reduced response to a second bronchoconstrictor challenge after recovery from the first, is well recognized with several indirect bronchoconstrictor challenges [1-3]. This may be an important physiological protective mechanism. However, the mechanisms involved in refractoriness are poorly understood. It has previously been shown that inhibitory prostaglandins may be responsible for part but not all of the refractoriness to challenges such as sodium metabisulphite (MBS) and exercise $[1,3]$, but other factors are clearly important.

Nitric oxide (NO) is a potential candidate for a bronchoprotective role in the refractory process as endogenous $\mathrm{NO}$ acts as a bronchodilator and neurotransmitter of inhibitory nonadrenergic noncholinergic (iNANC) nerves [4]. This might be particularly important with MBS since it is thought to cause bronchoconstriction via a neural mechanism, possibly NANC, which would be expected to cause NO release. It was hypothesized that endogenous NO produced during a first indirect bronchoconstrictor challenge might protect against subsequent challenge. If endogenous NO is involved in refractoriness then pretreatment with an inhibitor of NO production during a first challenge would prevent refractoriness induced by subsequent challenge. The authors therefore determined whether inhaled $N^{\mathrm{G}}$-mono-methyl-L-NMMA (L-NMMA) given immediately prior to an MBS challenge would prevent refractoriness in subjects with mild asthma.

\section{Materials and methods}

\section{Subjects}

Subjects with mild asthma, requiring inhaled $\beta$-agonist therapy only, were recruited from the City Hospital asthma register and screened for MBS refractoriness. Twenty subjects were screened and 11 had a refractory index (RI) of $\geq 30 \%$ (defined as the difference between the area under the curve (AUC) for the first and second challenge as a percentage of the values of the first challenge); 10 of these agreed to enter the double-blind phase of the study. Six subjects were atopic (two or more positive skin prick tests to common allergens), and all of them were nonsmokers. All subjects were symptom-free at the time of the study and had a forced expiratory volume in one second (FEV1) of $>70 \%$ predicted [5]. None of the participants had suffered an exacerbation of asthma or respiratory infection within 2 weeks of the study. The study was approved by the Nottingham City Hospital Ethics Committee. 


\section{Study design}

Subjects undertook two screening visits. On the first visit the provocative dose of MBS causing 20\% fall in FEV1 (PD20) was determined and on the second visit the RI to MBS was determined. Those showing an RI of $\geq 30 \%$ attended on two subsequent visits where they inhaled L-NMMA or placebo in a double-blind, cross over manner before having two sequential challenges with their PD20 dose of MBS.

\section{Methods}

$\beta$-agonist treatment was withheld for $6 \mathrm{~h}$ before each visit. Visits were separated by $\geq 2$ days and were performed at the same time of day. FEV1 was measured as the highest of two successive readings, within $100 \mathrm{~mL}$, on a dry wedge spirometer (Vitalograph, Buckingham, UK). The MBS PD20 was measured by giving increasing doses to a cumulative maximum of $76.9 \mu \mathrm{mol}$, using a MEFAR breath activated dosimeter (MEFAR, Brescia, Italy) as described previously [6].

\section{Screening visits}

Visit 1. In the first part of the study, subjects underwent an initial MBS challenge to determine their PD20 of MBS.

Visit 2. Subjects returned for a single dose challenge with the PD20 of MBS identified at the previous visit. FEV1 was measured before (baseline) and 2 min after inhalation of 3 puffs of normal saline (post-saline value) and at 1, 3, 5, 7, 10, 15 and $20 \mathrm{~min}$ after the MBS challenge. Subjects were rechallenged with the same dose of MBS immediately after recovery (FEV $1>95 \%$ of postsaline value) and FEV1 was measured at the same intervals for a further $20 \mathrm{~min}$. Subjects who had a reduction in AUC of the changes in FEV1 over $20 \mathrm{~min}$ at the second challenge of $\geq 30 \%$ were chosen to proceed to the second part of the study.

Visit 3 and 4: study of the effect of inhaled $\mathrm{N}^{G}$-monomethyl-L-arginine on the airway response to sodium metabisulphite. After baseline measurement of FEV1, each subject inhaled an aerosol of either L-NMMA (2 $\mathrm{mg}$ in $5 \mathrm{~mL} 0.9 \%$ saline) or placebo $(5 \mathrm{~mL}$ of $0.9 \%$ saline) in a double-blind, cross over study. The drug was administered via a jet nebulizer (Pari Master, Starnberg, Germany) driven by a compressed air source (147 kPa) with an output of $0.50 \mathrm{~g} \cdot \mathrm{min}^{-1}$. The subject inhaled the aerosolized solution at tidal breathing through a mouth piece until the nebulizer was dry. FEV1 was measured 5 min after finishing the aerosol delivery, and the subjects inhaled 3 puffs of normal saline and the FEV1 was measured again. The subjects were then challenged with MBS on two occasions as on visit 2.
Study of the effect of inhaled $\mathrm{N}^{G}$-mono-methyl-Larginine on exhaled nitric oxide levels

Exhaled NO was measured using a highly sensitive rapid chemiluminesence analyzer (LR2000, version 2.2; Logan Research, Rochester, UK) as previously described [7]. Three healthy nonsmoking control subjects without a history of asthma and/or wheeze were recruited from hospital staff and their exhaled NO levels were measured before (baseline) and 1, 15, and $60 \mathrm{~min}$ after inhalation of L-NMMA ( $2 \mathrm{mg}$ in $5 \mathrm{~mL} 0.9 \%$ saline).

\section{Analyses}

Sodium metabisulphite PD20 was calculated by linear interpolation of the log dose-response curve. The airway response to single dose challenge with MBS was expressed as maximum fall in $\mathrm{FEV} 1 \%$ and $\mathrm{AUC}$ in litres per minute for change from post-saline FEV $1>20 \mathrm{~min}$. An RI was derived by expressing the difference between AUC for the first and second challenge as a percentage of the values of the first challenge. Baseline FEV1, the maximum fall in FEV $1 \%$ and AUC for the first and second challenge and the RI were compared within subjects by student's paired ttest. Maximum fall in FEV1, AUC and RI for drug and placebo are presented as mean \pm SEM with $95 \%$ confidence interval $(\mathrm{CI})$ of the difference between the two treatments.

It was calculated that with $\geq 9$ subjects receiving both treatments, the study would have $95 \%$ power to detect a change in RI between two treatments of $15 \%$ (given an inter-subject standard deviation for repeat estimation of RI of $12 \%[3])$.

\section{Results}

\section{Baseline data from screening visits}

Challenge with the two single doses of MBS on the second screening visit caused a mean maximum fall in FEV 1 of $26 \pm 2.6 \%$ and $16 \pm 2.4 \%$ after the first and the second challenge, respectively (95\% CI $6.5-13.3 \%$, $\mathrm{p}<0.0001)$. The AUC was $11 \pm 2.7$ and $6 \pm 2 \mathrm{~L} \cdot \mathrm{min}^{-1}$ after the first and the second challenge, respectively (95\% CI $3-$ $6.9, \mathrm{p}<0.0001)$. The mean RI was $55 \pm 5.6 \%$.

Comparison of the effect of $\mathrm{N}^{G}$-mono-methyl-L-arginine and placebo (visits 3 and 4)

There was no significant difference between baseline FEV1 values on placebo and L-NMMA study days (3.33 \pm $0.26 \mathrm{~L}$ and $3.24 \pm 0.26 \mathrm{~L}$ respectively, $95 \% \mathrm{CI}-0.054-0.22$ $\mathrm{L}, \mathrm{p}=0.2)$.

There was no significant difference in FEV1 after placebo and L-NMMA $(3.2 \pm 0.2 \mathrm{~L}$ and $3.1 \pm 0.19 \mathrm{~L}$ respectively, $95 \% \mathrm{CI}-0.02-0.14 \mathrm{~L}, \mathrm{p}=0.16$ ).

There was no significant difference in the first challenge data between placebo and L-NMMA (mean maximum fall in FEV $1 \%$ was $26 \pm 2 \%$ and $27 \pm 2.8 \%$ respectively, $95 \%$ CI $-4.9-2.3 \%, \mathrm{p}=0.4$, AUC was $11 \pm 2.4$ and $10 \pm 2.2 \mathrm{~L} \cdot \mathrm{min}^{-1}$, respectively, $95 \%$ CI $-4.7-2.1, \mathrm{p}=0.6$ ). There was no significant difference in the second challenge data between placebo and I-NMMA (mean maximum fall in FEV1 was 
Table 1. - Effect of $N^{G}$-mono-methyl-L-arginine on refractorines to sodium metabisulphite (MBS)

\begin{tabular}{|c|c|c|c|c|c|c|}
\hline & \multirow[b]{2}{*}{$\underset{\mathrm{L}}{\text { Baseline FEV } 1}$} & \multicolumn{2}{|c|}{ 1st challenge } & \multicolumn{2}{|c|}{ 2nd challenge } & \multirow[b]{2}{*}{$\begin{array}{l}\text { RI } \\
\%\end{array}$} \\
\hline & & $\begin{array}{l}\text { Max. fall in } \\
\text { FEV } 1 \%\end{array}$ & $\underset{\mathrm{L} \cdot \mathrm{min}^{-1}}{\mathrm{AUC}}$ & $\begin{array}{l}\text { Max. fall in } \\
\text { FEV } 1 \%\end{array}$ & $\underset{\mathrm{L} \cdot \mathrm{min}^{-1}}{\mathrm{AUC}}$ & \\
\hline Assessment & 3.32 & 26 & 11 & 16 & 6 & 55 \\
\hline Placebo & 3.33 & 26 & 11 & 15 & 5 & 49 \\
\hline L-NMMA & 3.24 & 27 & 10 & 15 & 5 & 50 \\
\hline $95 \% \mathrm{CI}$ & $-0.05-0.2$ & $-4.7-2.3$ & $-1.2-2.1$ & $-6.16-4.6$ & $-1.7-1.7$ & $-20-18$ \\
\hline $\mathrm{p}$-value & 0.2 & 0.42 & 0.57 & 0.7 & 1.0 & 0.9 \\
\hline
\end{tabular}

Maximum fall in forced expiratory volume in one second (FEV1), area under the percentage change in FEV1 curve (AUC) over 20 min for the first and the second MBS challenge and refractory index (RI). Values are presented as mean, standard errors are given in text. 95\% CI: $95 \%$ confidence interval of the difference between placebo and L-NMMA.

$15 \pm 1.3 \%$ and $15 \pm 2.1 \%$ respectively, $95 \%$ CI $-6.1-4.6 \%$, $\mathrm{p}=0.7$, AUC was $4.94 \pm 0.9 \mathrm{~L} \cdot \mathrm{min}^{-1}$ for both, $95 \% \mathrm{CI}$ for difference $-1.7-1.7, p=0.99)$. There was no significant difference in the RI between placebo and L-NMMA $(49 \pm$ $6.9 \%$ and $50 \pm 7.3 \%$ respectively, 95\% CI for difference $-20-18, \mathrm{p}=0.89$ ) (table 1 and fig. 1).

The effect of inhaled $\mathrm{N}^{G}$-mono-methyl-L-arginine on exhaled nitric oxide levels

Exhaled NO levels were significantly lower after LNMMA treatment (fig. 2). Baseline exhaled NO level was $7.6 \pm 1.0$ parts per billion (ppb). Exhaled NO was $67 \pm$ $4.7 \%, 82 \pm 2.9 \%$ and $82 \pm 2.5 \%$ of baseline at 1,15 and 60 min, respectively $(\mathrm{p}<0.05$ at all time points).
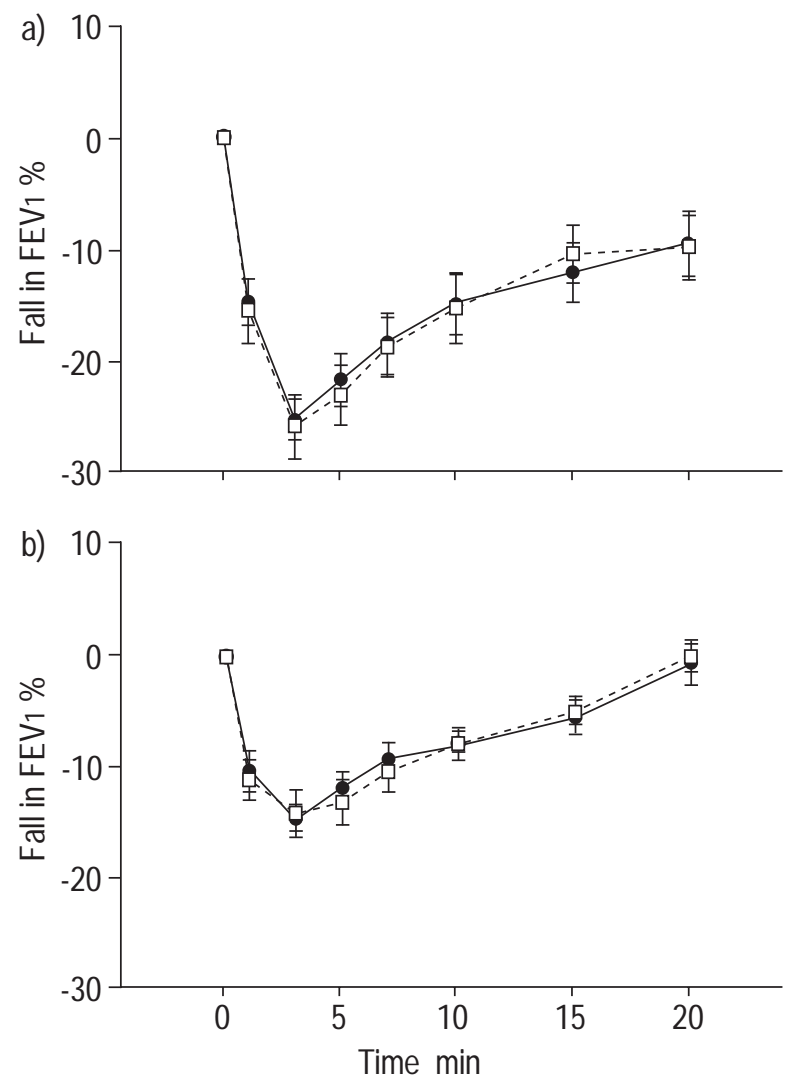

Fig. 1. - Mean \pm SEM change in forced expiratory volume in one second (FEV1), expressed as percentage fall from post-saline values, in a) first and b) second sodium metabisulphite (MBS) challenges after placebo and $N^{\mathrm{G}}$-mono-methyl-L-arginine (L-NMMA) treatment. $\bigcirc$ : placebo; $\square$ : L-NMMA.

\section{Discussion}

The aim of this study was to determine whether the (NOS) inhibitor, L-NMMA, would inhibit MBS-induced refractoriness, thus implicating NO in the refractoriness process. It was hypothesized that release of NO from iNANC nerves during a first bronchoconstrictor challenge would protect against a second challenge. Although evidence of refractoriness to MBS-induced bronchoconstriction was shown, L-NMMA had no effect on the MBS-induced refractoriness.

The study was carefully designed to try to maximize the chance of seeing an effect. Subjects were required to show a significant degree of MBS refractoriness ( $\geq 30 \%$ ) before entry into the double-blind phase. A dose of LNMMA which was twice as high as the dose with which RicCIARDOLO et al. [8] showed a marked effect on bradykinin-induced bronchoconstriction in mild asthmatic subjects was chosen. The nebulizer characteristics were comparable to those used by the latter group apart from a higher output by the current nebulizer. KHARITONOv et al. [9] showed that $1 \mathrm{mg}$ L-NMMA significantly decreased the peak exhaled NO in healthy control subjects for $\geq 30$ min. The current data confirm these findings as exhaled NO levels after inhalation of $2 \mathrm{mg}$ L-NMMA led to significant inhibition of exhaled NO levels for $\geq 1 \mathrm{~h}$. As all of the first MBS challenges were completed within 30 min and the second challenges proceeded within $10.5 \pm 2.3$ min after the first challenge, it was likely that the dose of L-NMMA chosen was pharmacologically active in the

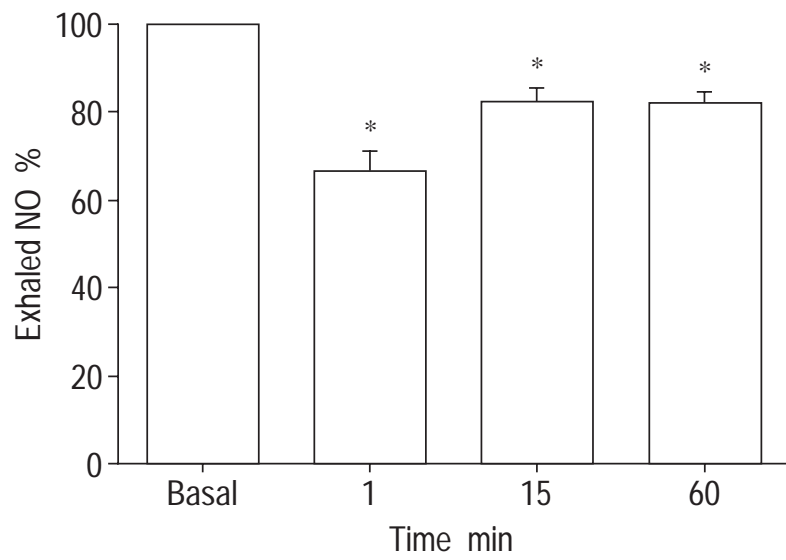

Fig. 2. - Mean \pm SEM change in exhaled nitric oxide (NO) levels, expressed as a percentage of baseline (basal) values, after $N^{\mathrm{G}}$-mono-methyl-Larginine (L-NMMA) treatment. *: $\mathrm{p}<0.05$ compared to baseline. 
airways during at least the first MBS challenge when it was postulated that NO would be released and could subsequently cause refractoriness to further challenge. This study investigated subjects who were not taking inhaled steroids, since steroids can suppress inducible (i)NOS induction [10]. This study had sufficient power to detect a change of RI of $15 \%$ in a group of subjects who had an RI of 55\% at baseline. The authors therefore feel confident in concluding from this study that $\mathrm{NO}$ is unlikely to play a major role in MBS refractoriness.

L-NMMA did not alter resting airway calibre suggesting that NO production is not functionally important in regulating resting airway tone. This agrees with previous findings that inhaled NOS inhibitors do not alter baseline airway calibre in asthmatic subjects $[11,12]$. The design of the study also enabled the investigators to comment on the effect of L-NMMA on the response to MBS per se. It was found to have no effect. This contrasts with studies showing that L-NMMA increases bronchoconstriction induced by bradykinin and methacholine in mild asthmatic subjects [8] although a further study in severe asthmatics showed no effect [13] and suggests that NO production may occur during bradykinin and cholinergic-induced contraction but not MBS-induced contraction.

In conclusion, it has been shown that repeated sodium metabisulphite challenge leads to refractoriness in subjects with mild asthma. The lack of an effect of $N^{\mathrm{G}}$-monomethyl-L-arginine suggests that endogenous nitric oxide synthesis does not contribute to baseline airway calibre, airway responsiveness to sodium metabisulphite nor sodium metabisulphite-induced refractoriness.

\section{References}

1. O'Byrne PM, Jones GL. The effect of indomethacin on exercise-induced bronchoconstriction and refractoriness after exercise. Am Rev Respir Dis 1986; 134: 69-72.

2. O'Hickey SP, Hawksworth RJ, Rees PJ, Lee TH. Effect of indomethacin on the refractory period to hypertonic saline-induced bronchoconstriction (Abstract). Am Rev Respir Dis 1990; 141: A655.
3. Pavord I, Wisniewski A, Tattersfield AE. Refractoriness to inhaled sodium metabisulphite in subjects with mild asthma. Eur Respir J 1994; 7: 50-54.

4. Belvisi MG, Stretton CD, Yacoub M, Barnes PJ. Nitric oxide is the endogenous neurotransmitter of bronchodilator nerves in humans. Eur J Pharmacol 1992; 210 : 221-222.

5. Quanjer P. Standardized lung function testing. Bull Eur Physiopathol Respir 1983; 19: Suppl. 5, 1-95.

6. Pavord I, Wisniewski A, Mathur R, Wahedna I, Knox AJ, Tattersfield AE. Effect of inhaled $\mathrm{PGE}_{2}$ on bronchial reactivity to sodium metabisulphite, and methacholine in patients with asthma. Thorax 1991; 46: 633-637.

7. Gabbay E, Fisher AJ, Small T, Leonard AJ, Corris PA. Exhaled single-breath nitric oxide measurements are reproducible, repeatable and reflect levels of nitric oxide found in the lower airways. Eur Respir J 1998; 11: 467472.

8. Ricciardolo FL, Geppetti P, Mistretta A, et al. Randomized double-blind placebo-controlled study of the effect of inhibition of nitric oxide synthesis in bradykinin induced asthma. Lancet 1996; 348: 374-377.

9. Kharitonov SA, Yates D, Robbins RA, Logan-Sindair $\mathrm{RB}$, Shinebourne EA, Barnes PJ. Increased nitric oxide in exhaled air of asthmatic patients. Lancet 1994; 343: 133135.

10. Radomski MW, Palmer RMJ, Moncada S. Glucocorticoids inhibit the expression of an inducible, but not the constitutive nitric oxide synthase in vascular endothelial cells. Proc Natl Acad Sci USA 1990; 87: 10043-10049.

11. Yates DH, Kharitonov SA, Robbins RA, Thomas PS, Barnes PJ. Effect of NO synthase inhibitor and a glucocoticoid on exhaled NO. Am J Respir Crit Care Med 1995; 152: 892-896.

12. Yates DH, Kharitonov SA, Thomas PS, Barnes PJ. Endogenous NO is decreased in asthmatic patients by an inhibitor of iNOS. Am J Respir Crit Care Med 1996; 154: 247-250.

13. Ricciardolo FLM, Di Maria GU, Mistretta A, Sapienza MA, Geppetti P. Impairment of bronchoprotection by nitric oxide in severe asthma. Lancet 1997; 350: $1297-$ 1298. 